\title{
The impact of ecbolic therapy in the early postpartum period on uterine involution and reproductive health in dairy cows
}

\author{
Cyril P. STEPHEN ${ }^{1,3,4) *}$, Walter H. JOHNSON ${ }^{1)}$, Stephen J. LEBLANC ${ }^{1}$, \\ Robert A. FOSTER ${ }^{2)}$ and Tracey S. CHENIER ${ }^{1)}$ \\ 1)Department of Population Medicine, Ontario Veterinary College, University of Guelph, Guelph, Ontario N1G 2W1, \\ Canada \\ ${ }^{2)}$ Department of Pathobiology, Ontario Veterinary College, University of Guelph, Guelph, Ontario N1G 2W1, \\ Canada \\ 3)School of Animal and Veterinary Sciences, Charles Sturt University, Wagga Wagga, NSW 2678, Australia \\ 4)Graham Centre for Agricultural Innovation, Charles Sturt University, Wagga Wagga, NSW 2678, Australia
}

J. Vet. Med. Sci.

81(3): 491-498, 2019

doi: 10.1292/jvms.18-0617

Received: 1 November 2018 Accepted: 13 January 2019

Published online in J-STAGE: 5 February 2019

\begin{abstract}
Postpartum uterine disease due to poor uterine involution continues to be a significant factor that contributes to poor reproductive efficiency in dairy cattle. Therapy that increases the frequency, duration and strength of uterine contractions in the postpartum period might enhance uterine involution, resulting in improved reproductive performance. The objective of this clinical trial was to study the effect of two uterine ecbolic therapies, oxytocin and prostaglandinF2a on uterine involution, postpartum endometritis, and reproductive performance. A randomized double-blinded clinical trial was conducted in 118 dairy cows from two research herds that had normal parturition and expulsion of the fetal membranes. Within $24 \mathrm{hr}$ after calving, cows were randomly assigned to receive intramuscular injections twice a day of $50 \mathrm{IU}$ of oxytocin, or $25 \mathrm{mg}$ of dinoprost (PGF2a) or saline (control) for 7 days. Cows were monitored from day 3 to day $63 \pm 3$ days postpartum by transrectal palpation of the uterus, vaginoscopy, Metricheck ${ }^{\otimes}$ examination and by endometrial cytology. Blood samples were collected for measurement of progesterone in weeks 3 ( $21 \pm 3$ days), 5 ( $35 \pm 3$ days), 7 ( $49 \pm 3$ days), and 9 ( $63 \pm 3$ days) postpartum. Herd breeding records were obtained to determine reproductive performance in all cows. Neither oxytocin nor prostaglandin F2a therapy during the first week postpartum had any significant effect on the rate of uterine involution, prevalence of endometritis or reproductive performance, compared to untreated controls. Ecbolic drugs, as used here, are not recommended for use in clinical practice to improve involution or reproductive tract health in normal cows.

KEY WORDS: ecbolic, endometritis, postpartum cow, uterine involution
\end{abstract}

Reproduction plays a pivotal role in successful dairy production. Reproductive tract disease may substantially impair performance $[15,23,46]$. Delay in uterine involution significantly affects fertility and reproductive performance [5, 9, 18, 39, 45]. Treatments that enhance or accelerate uterine involution, or reduce the incidence of uterine disease may increase reproductive efficiency. It has been suggested that ecbolic drugs like oxytocin and prostaglandin F2 $\alpha$ (PGF2 $\alpha$ ) could be used as preventative treatments to enhance uterine involution by promoting uterine contraction and clearance of debris and fluid, and potentially improve reproductive performance $[2,5]$. The normal bovine uterus shows a progressive decrease in contractility over time postpartum [3]. By $24 \mathrm{hr}$ post calving, the frequency, amplitude, and duration of myometrial contractions decrease by over $50 \%$ compared to the immediate postpartum period [28].

Ecbolic therapy in postpartum cows is controversial as many published reports used low numbers of animals, were limited to only one or two interventions, lacked controls, concurrently used other drugs, or were not conducted during the early postpartum period. Several studies investigated the effect of administration of PGF $2 \alpha$ or its analogues within 40 days of calving on reproductive performance in cattle [16]. However, only limited studies have evaluated the effect during the early postpartum period, especially during the first week after calving. In vitro studies on myometrial strips demonstrated that PGF2 $\alpha$ always increased uterine contractility, but the response was not dose dependent. A linear stimulatory effect with increasing doses was noticed when oxytocin was used [35]. In a widely-cited case series involving only three cows and no control group, Lindell et al., suggested that exogenous prostaglandin used twice daily for 10 days, starting day 3 postpartum, accelerated uterine involution 
by 6 to 13 days [25]. The time for uterine involution in this study, based upon size, location and tone of uterus and symmetry of uterine horns as determined by transrectal palpation (every second day following calving), was 20 days. The authors proposed that prostaglandin administration increased the rate of uterine involution in postpartum dairy cows by increasing myometrial contractility. Another study compared the uterotonic effects of intramuscular injections of PGF2 $\alpha$ and oxytocin in six mixed-breed beef cows 48 to $72 \mathrm{hr}$ after parturition [11]. Uterine motility, as assessed using a miniature pressure transducer placed in one uterine horn, increased 9-fold when oxytocin was administered by intramuscular injection compared to PGF2 $\alpha$ also administered by intramuscular injection. Stolla et al. (1990), found the uterotonic effects of prostaglandin analogues luprostiol, tiaprost and cloprostenol to be less than dinoprost, the natural PGF2 $\alpha$ [44]. The effects of luteolytic doses of dinoprost (25 mg), d-cloprostenol $(150 \mu \mathrm{g})$, dl-cloprostenol $(500 \mu \mathrm{g})$ and placebo were compared during diestrus in experimental cows [19]. Dinoprost yielded the most pronounced effect on uterine motility, followed by dl-cloprostenol. A single intramuscular injection of oxytocin or carbetocin (long acting analogue of oxytocin) did not prolong the uterotonic effect in postpartum dairy cows [2]. Another study indicated no difference in the incidence of endometritis or median interval from calving to pregnancy when a single injection of either oxytocin or carbetocin was administered within $6 \mathrm{hr}$ of calving in dairy cows [5]. A clinical trial conducted in crossbred Zebu cows where two injections of oxytocin where administered intramuscularly immediately after calving and $6 \mathrm{hr}$ later respectively did not improve reproductive performance [34].

The objective of this study was to assess the effect of repeated early postpartum administration of oxytocin or PGF $2 \alpha$ on uterine involution and reproductive performance. The hypothesis was that using either prostaglandin or oxytocin would accelerate uterine involution in postpartum dairy cows, resulting in reduced postpartum reproductive tract disease and improved reproductive performance.

\section{MATERIALS AND METHODS}

\section{Experimental design}

A double-blinded clinical trial using 118 cows was conducted at the Elora and Ponsonby Dairy Research stations of the University of Guelph, Canada. A sample size of 39 cows per treatment group allowed for detection of a difference from 15 to 30 days in median time to involution with a 63 day study period using time-to-event analysis [1]. All use of animals and procedures were approved by the Animal Care and Ethics Committee of the University of Guelph-AUP 08R071. Enrolled cows were clinically normal postpartum Holstein dairy cows, between 1st and 5th lactation, with a normal parturition and expulsion of fetal membranes within $24 \mathrm{hr}$ postpartum. Normal parturition was defined as either unassisted calving or assistance by one member of farm staff for $<10 \mathrm{~min}$, without use of a calving jack, and with vaginal delivery of the calf. Cows were randomly assigned within $24 \mathrm{hr}$ after parturition to one of the three treatments. The treatments were administered by intramuscular injection twice daily before milking at 5:00 am and 3:00 pm for 7 days. The treatments consisted either 50 IU oxytocin (OxytoSure, Vetoquinol Ltd., Canada) (n=40 cows) or 25 mg PGF2 $\alpha$ (Lutalyse, Pfizer Animal Health, Canada) ( $\mathrm{n}=42$ ); or $5 \mathrm{ml} 0.9 \%$ sodium chloride solution ( $\mathrm{n}=36$ ). The injections were pre-loaded in $5 \mathrm{~m} l$ disposable syringes, labelled only as A, B, or C and administered by farm staff blinded to the treatments.

\section{Animal assessments}

Examinations were performed on days 3 and 7 postpartum, then repeated on every Monday and Thursday until week $9(63 \pm$ 3 days) postpartum. Each examination consisted of transrectal palpation, vaginoscopy, and a Metricheck ${ }^{\circledR}$ (Simcro, Hamilton, New Zealand) examination. Endometrial samples were collected for cytological examination using a cytobrush (VWR CanLab, Mississauga, ON, Canada). This was performed first on day 7, then weekly until $30 \pm 3$ days postpartum, and then once every two weeks until week 9 ( $63 \pm 3$ days) postpartum. Blood was collected from coccygeal vein in weeks 3 ( $21 \pm 3$ days), 5 (35 \pm 3 days), 7 (49 \pm 3 days), and 9 (63 \pm 3 days) for measurement of progesterone concentrations in serum. All diagnostic procedures were performed by the same veterinarian in the same sequence (rectal palpation followed by vaginoscopic examination, Metricheck ${ }^{\circledR}$ examination, and endometrial cell collection).

The location of the uterus was determined by transrectal manual palpation beginning on day 3 postpartum and was classified as: uterus over the pelvic brim and not completely palpable; uterus over the pelvic brim but completely palpable after retraction; or uterus entirely within the pelvis before retraction. These were performed by a veterinarian with more than 10 years of experience in cattle reproductive work.

In addition to assessment of individual animals, the median time to first AI, and the median time to pregnancy was determined by analysis of herd breeding records maintained electronically at both research stations.

\section{Diameter of the uterine horns and cervix}

The diameter in centimeters $(\mathrm{cm})$ of the base of the previously gravid and non-gravid horns were assessed by transrectal palpation beginning on day 3 postpartum. This was estimated by manual measurement, as the large size of the uterus in the initial stages did not permit ultrasonographic imaging of the entire cross-sectional area of the uterine horns. The uterine horns were considered symmetrical when uterine horn diameters were within $1 \mathrm{~cm}$ of another, and no further changes in diameter could be appreciated during two successive examinations. A difference of $1 \mathrm{~cm}$ in diameter was considered symmetric as it can be affected by parity. The diameter of the cervix was assessed manually by rectal palpation starting day 3 postpartum as a complete transverse placement of the linear rectal probe was difficult to measure the cervical diameter. The diameter was categorized as $<5 \mathrm{~cm}, 5$ to $7.5 \mathrm{~cm}$, or $>7.5 \mathrm{~cm}$. 


\section{Endometrial cytology}

Endometrial cytology was performed using the method described by Kasimanickam et al., starting day 7 postpartum [21, 22]. Cows were sampled once a week until 30 days postpartum and then once every two weeks until week 9 (63 \pm 3 days) postpartum. A different approach was taken to obtain day 7 postpartum samples, as it was difficult to straighten the cervix in the early postpartum cow, with the uterus pulled over the pelvic brim. After threading the cytobrush, the inner steel rod was introduced into the outer flexible plastic tubing of a mare uterine swab and introduced vaginally. The cervix was located with the index finger and the tip of the tube with the intact cap was guided through the cervical canal. Once in place, the inner rod was pushed to open the cap, the cytobrush advanced into the uterus to contact the uterine wall, rolled clockwise, and then retracted back into the outer plastic tubing. The device was rinsed with water and sterilized using Germiphene (Germiphene Corp., Brantford, ON, Canada) between uses.

The cytobrush was immediately rolled onto a labelled clean glass microscope slide, air dried, and fixed with a cytofixative (Cytoprep $^{\circledR}$, Fisher Scientific Ltd., Nepean, ON, Canada). The slides were later stained with a modified Giemsa stain (ProtocolHema ${ }^{\circledR}$, Biochemical Sciences Inc., Swedesboro, NJ, U.S.A.).

The percentage of neutrophils was determined by counting a minimum of 200 cells (endometrial epithelial cells and neutrophils) at 400X magnification under light microscopy (Nikon Eclipse 50i; Nikon Corporation, Tokyo, Japan). All slides were assessed by two independent blinded observers. Endometritis was diagnosed using two different $\%$ neutrophil cut-off values: $>5 \%$ neutrophils $[14]$ and $>10 \%$ neutrophils [21].

\section{Vaginoscopic and Metricheck ${ }^{\circledR}$ examination}

Vaginoscope and Metricheck ${ }^{\circledR}$ examinations were conducted to assess discharge in the vagina. The discharge was scored according to the color, consistency and odor of the contents. The vaginal discharge scores were graded according to the following scale: 0 -no discharge; 1 -clear mucus; 2 -flecks of purulent material in otherwise clear mucus; 3 -mucopurulent with less than 50\% purulent material; 4 -yellowish or brownish discharge with $>50 \%$ purulent material and no foul smell; 5 -yellowish or brownish discharge with $>50 \%$ purulent material with foul smell. After cleaning the vulva with paper towels, a disposable vaginoscope illuminated with a penlight was used to visualize the external cervical os and cranial vagina. The Metricheck ${ }^{\circledR}$ device was introduced into the vaginal canal through the vulva, until reaching the vaginal fornix, and then retrieved to visualize the contents obtained from the cranial vagina. The Metricheck ${ }^{\circledR}$ device was cleaned and then sterilized using Germiphene between successive examinations.

\section{Criteria for diagnosis of reproductive tract disease}

A combined score of the vaginoscopic and Metricheck ${ }^{\circledR}$ examination was used to diagnose a purulent vaginal discharge (PVD). The scores were collapsed into endometritis negative (scores $\leq 2$ ) or endometritis positive (scores $>2$ ). Based on the work of LeBlanc et al., when vaginoscope and Metricheck ${ }^{\circledR}$ score were $\leq 2$, the cow was considered negative for PVD [24]. When vaginoscopic and Metricheck ${ }^{\circledR}$ score were both $\geq 3$ or vaginoscopic exam score was $\leq 2$ but Metricheck ${ }^{\circledR}$ exam score was $\geq 3$, the cow was considered to have PVD. There were no cases where vaginoscopic examination score was $\geq 3$ and Metricheck ${ }^{\circledR}$ exam $^{-}$ score was $\leq 2$. Endometrial cytology smears were classified as having endometritis when the proportion of neutrophils was either above $5 \%$ or above $10 \%$, and both levels were used for the entire duration of the study.

\section{Measurement of serum progesterone concentrations}

Blood samples were collected in weeks 3 ( $21 \pm 3$ days), 5 (35 \pm 3 days), 7 (49 \pm 3 days), and 9 (63 \pm 3 days) postpartum in 10 $\mathrm{m} l$ serum vacuum tubes from the coccygeal vein for measurement of progesterone. The blood samples were left undisturbed for $1 \mathrm{hr}$ and then centrifuged at 2,200 $\times \mathrm{g}$ for $10 \mathrm{~min}$ to separate the serum. The serum was transferred into labelled tubes and stored at $-20^{\circ} \mathrm{C}$. Progesterone concentration was measured at the Animal Health Laboratory of the University of Guelph by sequential competitive immunoassay technique with an analytical sensitivity of $0.2 \mathrm{ng} / \mathrm{m} l$ (Immulite ${ }^{\circledR}$, Siemens, Mississauga, ON, Canada). The intra- and inter-assay coefficients of variation were 6.3 and $5.8 \%$, respectively. A cow was considered cyclic when the serum progesterone concentration was $>3.2 \mathrm{nmol} / l[10]$.

\section{Data management and statistical analysis}

Data analysis was performed using SAS version 9.1 (SAS Institute Inc., Cary, NC, U.S.A.) with cow as the unit of concern. Individual outcome variables (diameter of the previously gravid and non-gravid horn, diameter of the cervix, location of the uterus, endometrial cytology, vaginoscopic and Metricheck ${ }^{\circledR}$ score, and serum progesterone value) were examined over time by treatment group and also overall.

The Mixed procedure of general linear models using standard one-way ANOVA was used to compare the time at which symmetry of the uterine horns was achieved, and the first time at which the uterus was intra- pelvic, after logarithmic transformation of data.

The chi-square statistic (Proc Freq) using Fisher's exact test was used to assess the association of treatment with resumption of ovulation based on serum progesterone at each sample time, prevalence of PVD, and prevalence of subclinical endometritis.

The Generalized Linear Mixed Model (GLIMMIX) procedure was used to analyze the cervical diameter over repeated measures postpartum. Least square means were calculated to estimate the probability of having cervical diameter greater than $5 \mathrm{~cm}$ after 3 weeks postpartum in each treatment group. 


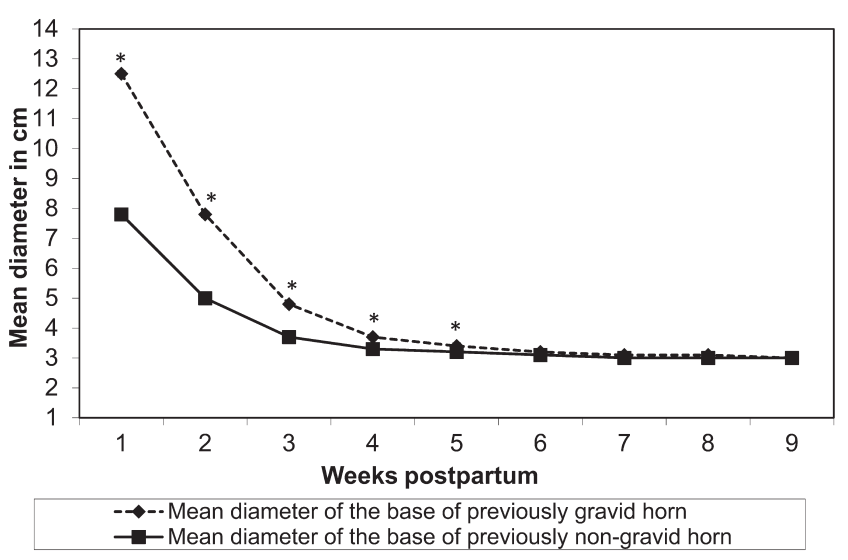

Fig. 1. The rate of involution of the previously gravid and nongravid horns irrespective of treatment groups. The difference between the diameter of the previously gravid and non-gravid horn was significant up to week $5(P<0.05$, indicated by *). The median time to symmetry was 19 days.

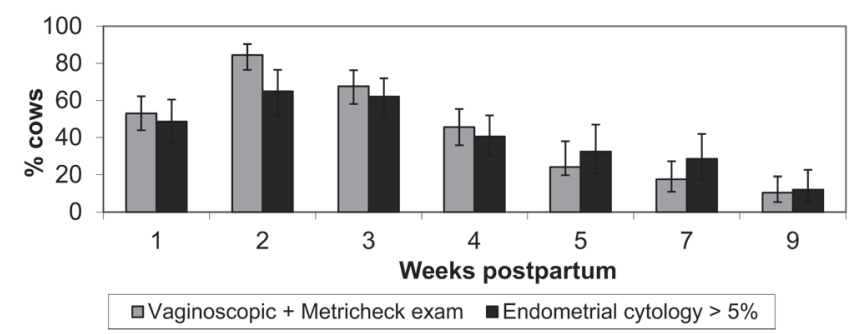

Fig. 2. The prevalence (mean $\% \pm 95 \% \mathrm{CI}$ ) of purulent vaginal discharge or $>5 \%$ neutrophils in endometrial cytology in 118 cows randomly assigned to receive oxytocin, prostaglandin F2 $\alpha$ or saline in the first week postpartum. There was no effect of treatment on these outcomes.

Survival analysis (Lifetest procedure of SAS and Log-Rank test) was used to assess the median time to first AI, and to pregnancy. The probability of pregnancy at first service was estimated using the chi-square statistic (frequency procedure) Fisher's exact test.

\section{RESULTS}

\section{Rate of uterine and cervical involution}

There was no significant difference $(P=0.91)$ in the mean diameters of the previously gravid and non-gravid horns among treatments at the end of the study. The involution of the previously gravid and non-gravid horns irrespective of treatment is shown in Fig. 1. The median time to uterine horn symmetry was not significantly different between treatment groups. The overall median time to symmetry of horns was 19 days ( $95 \%$ confidence interval of 18 to 20 days). There was no significant difference among treatment groups in the time for the uterus to involute to the point it was entirely located within the pelvic cavity. The overall median time to first occurrence of the uterus completely within the pelvis irrespective of treatment was 21 days (95\% confidence interval of 20 to 22 days). Cervical diameter decreased over time (52, 6, 2 and $<1 \%$ of cows $>5 \mathrm{~cm}$ at weeks $3,5,7$, and 9 postpartum, respectively) but there was no treatment effect on the diameter of the cervix.

\section{Progesterone concentration profile and postpartum cyclicity}

Mean serum progesterone concentrations were not statistically different $(P>0.53)$ among the treatment groups at days $21,35,49$ and 63. Irrespective of the treatment groups, there were 34, 40, 51, and 59\% of cows with serum progesterone above this threshold at weeks, 3, 5, 7, and 9 postpartum, respectively; $85 \%$ cows had at least one ovulation in this time based upon progesterone concentration profiles. There was no difference $(P=0.88)$ in these proportions among treatment groups.

\section{Prevalence of clinical endometritis}

There was no treatment effect on the prevalence of PVD after 3 weeks postpartum $(P=0.52)$. Since there was no statistical difference between treatments on prevalence of clinical endometritis, an overall estimate irrespective of the treatment groups was made and prevalence was found to be $55 \%$. The prevalence of clinical endometritis by week postpartum is shown in Fig. 2 . There was a progressive decrease in the proportion of cows with clinical endometritis after 3 weeks. The cases of clinical endometritis within a week were not significantly different between treatments. The mean percentage of neutrophils in endometrial cytology was not different between treatment groups $(P=0.23)$ but progressively decreased over time postpartum (Fig. 3). The proportions of cows with $>5 \%$ or $>10 \%$ neutrophils in endometrial smears (Fig. 4) did not differ $(P>0.25)$ among treatments.

Figure 2 presents the prevalence of PVD and endometritis during the study period. More cows had purulent discharge up to 4 weeks postpartum whereas in weeks 5 and 7, endometritis was more prevalent.

The overall median time to first AI was 87 days ( $86.5,87$ and 88 for oxytocin, prostaglandin and control groups respectively) ( $95 \%$ confidence interval of 80 to 95 days) and to pregnancy was 170 days (176, 172 and 155 for oxytocin, prostaglandin and control groups respectively) (95\% confidence interval of 150 to 184 days), and these did not differ among treatments (Figs. 5 and 6). 


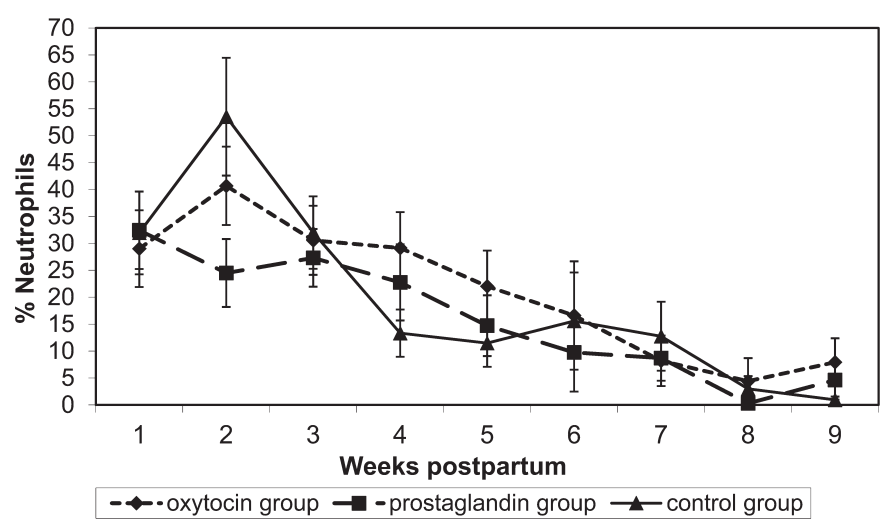

Fig. 3. The proportion of neutrophils in endometrial cytology (mean $\pm \mathrm{SE}$ ) in 118 dairy cows randomly assigned to receive oxytocin, prostaglandin $\mathrm{F} 2 \alpha$, or saline twice daily from 1 to 7 days postpartum.

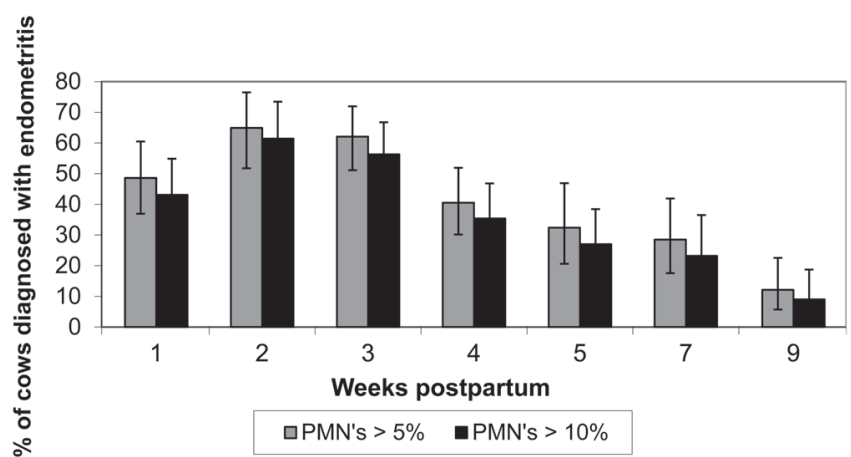

Fig. 4. The prevalence (mean $\% \pm 95 \% \mathrm{CI}$ ) of $>5 \%$ or $>10 \%$ neutrophils in endometrial cytology in 118 cows randomly assigned to receive oxytocin, prostaglandin F2 $\alpha$ or saline in the first week postpartum. There was no effect of treatment on these outcomes.

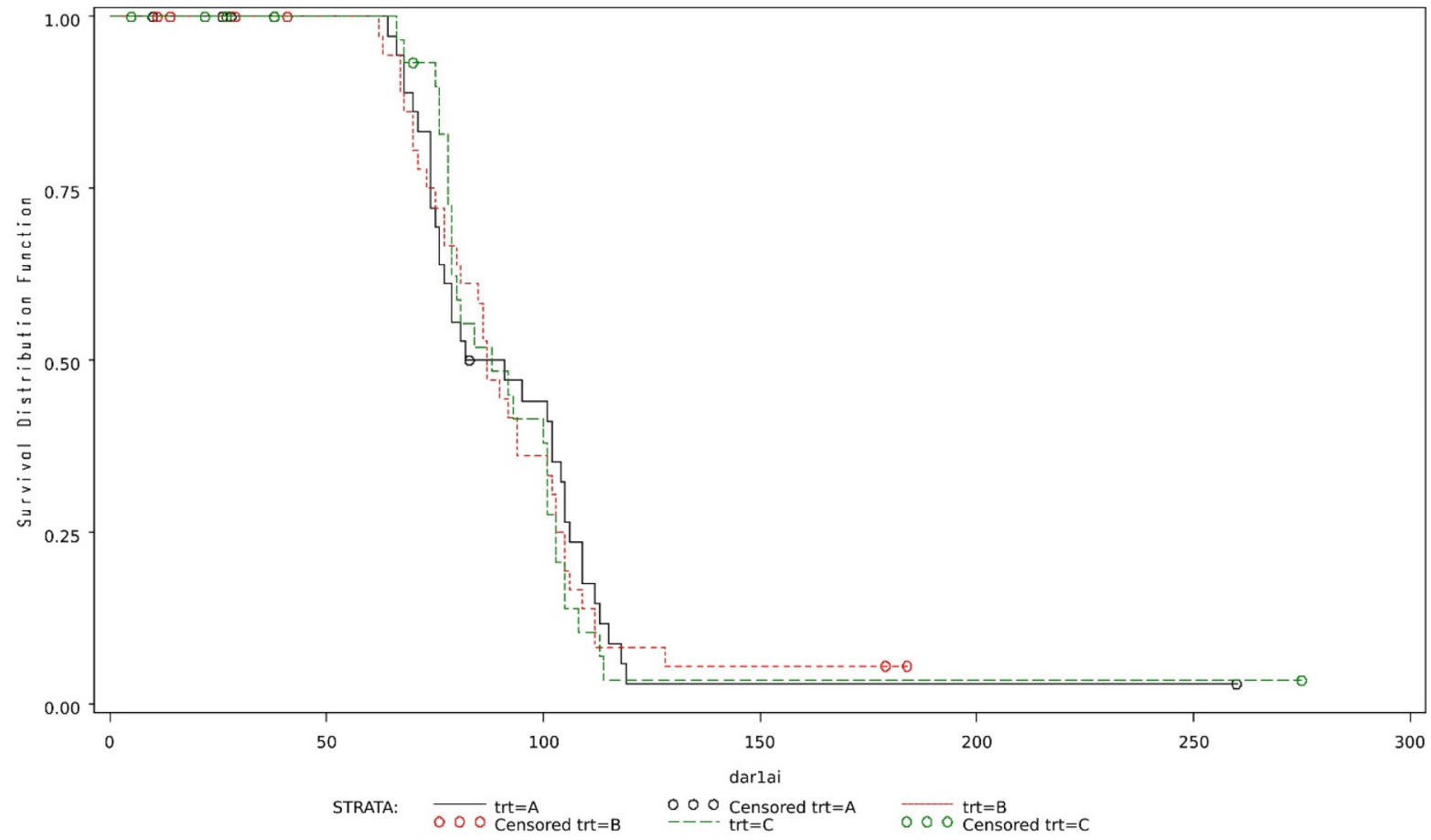

Fig. 5. Survival curves of days to first AI in cows in different treatment groups (Legend-Trt A-Oxytocin; Trt B-Prostaglandin F2 $\alpha$; Trt C-Control). The $\mathrm{x}$-axis represents the number of days postpartum whereas the $\mathrm{y}$-axis represents the proportion of cows that were not inseminated at a particular day postpartum.

\section{DISCUSSION}

There was no difference in uterine involution and reproductive outcome between ecbolic treatments, and between ecbolic treatments and normal controls. This is the first study to closely monitor rate of uterine involution and prevalence of endometritis for a full 9 weeks in postpartum dairy cows. Gross uterine involution was assessed by time to symmetry of uterine horns, intrapelvic location of the uterus, and cervical diameter less than $5 \mathrm{~cm}$. The overall median time to symmetry was 19 days, which is in agreement with studies reported in the literature [41, 43]. However, other studies reported an average of 40 days for achieving uterine horn symmetry determined by ultrasonography $[20,32]$. Based on our findings, within the power of the study, there does not appear to be any beneficial effect of ecbolic therapy with oxytocin (OxytoSure) or PGF2 $\alpha$ (Lutalyse) as administered, on accelerating gross uterine involution in postpartum cows. 


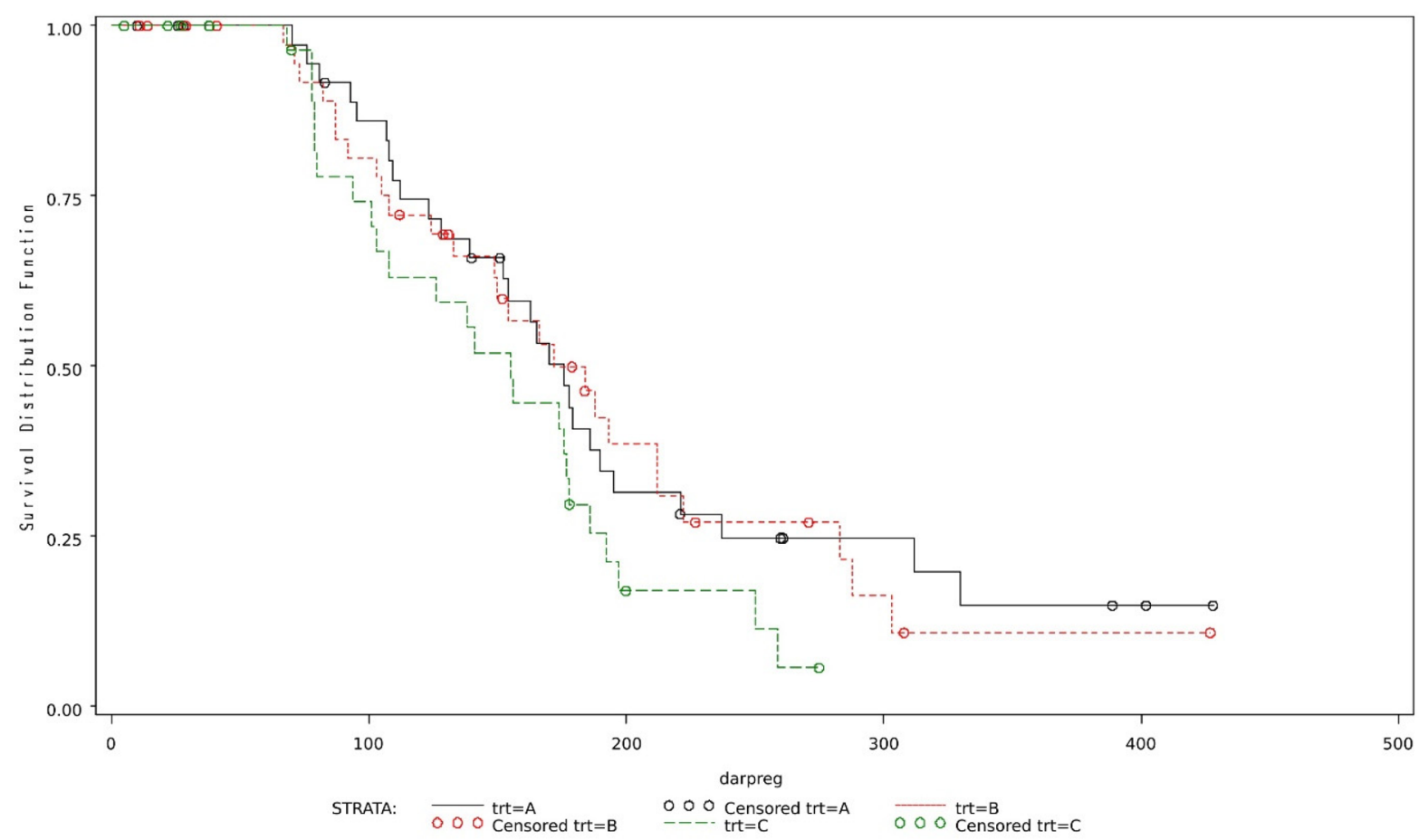

Fig. 6. Survival curves of time to pregnancy in cows in different treatment groups (Legend-Trt A-Oxytocin; Trt B-Prostaglandin F2 $\alpha$; Trt C-Control). The $\mathrm{x}$-axis represents the number of days postpartum whereas the $\mathrm{y}$-axis represents the proportion of cows that were not pregnant at a particular day postpartum.

Postpartum ecbolic therapy used here did not have a beneficial effect on resumption of cyclicity. Based on the combined data of the three treatment groups, about $85 \%$ of the cows had at least one ovulation between days 21 and 63 . Previous studies have reported that the first postpartum ovulation in cows with uterine infections is delayed [27, 31, 33, 42]. Mean interval from parturition to first ovulation was 34.4 days in cows with abnormal postpartum periods [31]. Cows with uterine disease are less likely to ovulate the first dominant follicle ( 8 vs $40 \%$ ) and more likely to have abnormal progesterone profiles (58 vs $39 \%)$ than normal cows [42].

There was no effect of treatment on the prevalence of endometritis. Based on the combined data, $46 \%$ of cows were diagnosed with endometritis at week 4 , and the prevalence declined to $24 \%$ by week 5 . Our results indicate higher prevalence of endometritis compared to other studies that report prevalence of $17 \%$ as diagnosed by vaginoscopic examination or cervical diameter $>7.5 \mathrm{~cm}$ between 20 and 33 days postpartum [24]; and 10.4\% as diagnosed using vaginoscopy alone between 28 and 41 days postpartum [4]. The prevalence of endometritis varies widely in the literature, which is mostly attributable to differences in diagnostic criteria and methods. We used a combination of vaginoscopy and Metricheck ${ }^{\circledR}$ to diagnose endometritis in our study. This was because we were concerned that the use of Metricheck ${ }^{\circledR}$ alone in early postpartum period may lead to false positives. However, in the present study, there were no cases where vaginoscopy was positive and Metricheck ${ }^{\circledR}$ was negative, implying the additional use of vaginoscopy does not improve the ability to diagnose endometritis. This could be one of the reasons why the prevalence estimates in our study is higher than estimates reported in other comparable studies. In a similar study in cows with a history of peripartum

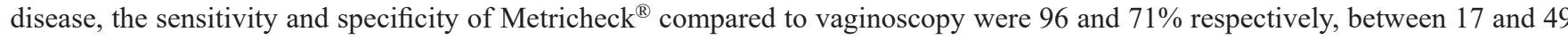
days postpartum [29].

In the present study, the prevalence of subclinical endometritis in the combined data, was 35.4 or $40.5 \%$ at 4 weeks postpartum, based on cytology with either 10 or 5\% neutrophil thresholds respectively. Comparable studies have reported the prevalence of subclinical endometritis to be $53 \%$ at 40 to 60 days postpartum [14]; $41 \%$ between 34 and 47 days postpartum [21]; or 11.8\% between 28 and 41 days postpartum [4]. Again, the variability in these reported estimates is likely attributable to differences in diagnostic criteria and the time period in which prevalence was estimated.

Ecbolic therapy in the form of either oxytocin or prostaglandin, did not improve overall reproductive performance compared to untreated controls. The median time to first AI and to pregnancy were higher ( 87 and 170 respectively) when compared to other studies and there was no significant difference between the treatments. The higher than normal time to pregnancy could likely be due to repeated endometrial sampling, which was a unique aspect of our study. Other comparable studies [4, 14, 21], have relied on sampling the uterus either once or on two occasions.

A previous in vitro study in our laboratory demonstrated the presence of immunoreactive oxytocin receptors (OTR) during the first week postpartum [36]; but the functionality of these OTR was unknown. The current study was performed to characterize OTR receptor functionality, however this randomized controlled clinical trial did not demonstrate any beneficial effect of treatment 
with oxytocin on uterine involution. This suggests agonist-induced desensitization of the oxytocin receptor (OTR) which occurs when target cells and receptors are exposed to high concentrations of hormone $[7,37,38]$. Binding of the agonist with OTR results in removal of agonist-activated cell surface receptors from the plasma membrane into the intracellular compartment where they cannot be accessed by agonists present in extracellular fluid [12]. During the postpartum period, the episodic release of endogenous oxytocin in response to milking stimuli, and repeated sampling that involved genital manipulation would have resulted in substantial release of endogenous oxytocin. Schams et al., proposed that the endogenous oxytocin release in cows in response to stimulation of vagino-cervical area is greater than that which occurs during mammary stimulation [40]. In the present study, agonist desensitization may have resulted in receptors not being available at the time of treatment. The drug was injected very close to milking time, and in most of the cows it becomes a conditioned reflex to release endogenous oxytocin to let down milk during milking [6].

Similarly, during the early postpartum period large amounts of endogenous prostaglandin is released from the endometrium, as detected by elevated PGFM (prostaglandinF2 $\alpha$ metabolites) concentration in the plasma [26]. Endogenous oxytocin stimulates release of PGF $2 \alpha$ from the non-pregnant bovine uterus and the combined action produces uterine contractions [13]. Therefore, injecting the cows with prostaglandin over and above the typical physiological levels, might have downregulated target cell responsiveness to exogenous PGF $2 \alpha$ resulting in no beneficial effect. Conversely, the response of the uterus directly or indirectly to PGF2 $\alpha$ may already be maximally stimulated without exogenous administration of PGF2 $\alpha$. This study did not measure the PGFM levels that would have differentiated cows with normal from those with abnormal level of endogenous prostaglandin.

The dosage and frequency of oxytocin administration used in this study was chosen based on previous studies that failed to elicit a uterine response with either a lower dose or lesser frequency of administration. One study reported that the endogenous oxytocin released during milking is equivalent to blood levels achieved after injecting $0.5 \mathrm{IU}$ of exogenous oxytocin [8]. In that study a dose of 0.5 or 2 IU of oxytocin increased the intramammary pressure to the maximum but there was very little uterine response, which indicates that oxytocin released during normal milking may not affect uterine contractility. They found that a dose greater than 2 IU was required to elicit significant uterine contractions and the maximal response was noticed with 4 IU of oxytocin. We are unaware of published studies investigating peripheral oxytocin concentrations during the early postpartum period in response to genital manipulation in cows. Oxytocin doses of about 60 IU have been found to produce spasmodic contractions in cows with retained placenta $[17,30]$. A single dose of 50 IU oxytocin showed a significant short-term effect on uterine contractility in postpartum dairy cows [2]. In this study, $50 \mathrm{IU}$ oxytocin was injected twice daily and should have been adequate to result in myometrial contractions. There is no information about the effects of endogenous oxytocin during the early postpartum period, when progesterone and estrogen concentrations are very low.

In this clinical trial, there was no significant effect of ecbolic therapy on the rate of uterine involution. Neither oxytocin nor PGF $2 \alpha$ therapy during the first week postpartum had any significant effect on uterine involution, resumption of cyclicity, prevalence of reproductive tract disease, or reproductive performance compared to controls. Therefore, these drugs, as used here, are not recommended for use in clinical practice to improve involution or reproductive tract health.

ACKNOWLEDGMENTS. The authors thank Laura Wright and staff of Elora and Ponsonby Dairy Research Stations for the help and support provided during the clinical trial. We acknowledge the support of Pfizer Animal Health Canada and Vetoquinol Canada in providing drugs and partial financial support for this research project. We also acknowledge the support from the Ontario Ministry for Agriculture and Rural Affairs for providing the animals in this clinical trial. Help from William Sears and Anne Valliant with the statistical analysis is greatly appreciated.

\section{REFERENCES}

1. Abramson, J. H. 2011. WINPEPI updated: computer programs for epidemiologists, and their teaching potential. Epidemiol. Perspect. Innov. 8: $1-9$. [Medline] [CrossRef]

2. Bajcsy, A. C., Szenci, O., van der Weijden, G. C., Doornenbal, A., Maassen, F., Bartyik, J. and Taverne, M. A. 2006. The effect of a single oxytocin or carbetocin treatment on uterine contractility in early postpartum dairy cows. Theriogenology 65: 400-414. [Medline] [CrossRef]

3. Bajcsy, A. C., Szenci, O., Doornenbal, A., van der Weijden, G. C., Csorba, C., Kocsis, L., Szucs, I., Ostgard, S. and Taverne, M. A. 2005. Characteristics of bovine early puerperal uterine contractility recorded under farm conditions. Theriogenology 64: 99-111. [Medline] [CrossRef]

4. Barlund, C. S., Carruthers, T. D., Waldner, C. L. and Palmer, C. W. 2008. A comparison of diagnostic techniques for postpartum endometritis in dairy cattle. Theriogenology 69: 714-723. [Medline] [CrossRef]

5. Barrett, A. J., Murray, R. D., Christley, R. M., Dobson, H. and Smith, R. F. 2009. Effects of the administration of oxytocin or carbetocin to dairy cows at parturition on their subsequent fertility. Vet. Rec. 165: 623-626. [Medline] [CrossRef]

6. Bruckmaier, R. M. and Blum, J. W. 1998. Oxytocin release and milk removal in ruminants. J. Dairy Sci. 81: 939-949. [Medline] [CrossRef]

7. Bruckmaier, R. M. 2003. Chronic oxytocin treatment causes reduced milk ejection in dairy cows. J. Dairy Res. 70: 123-126. [Medline] [CrossRef]

8. Cooper, M. D. and Foote, R. H. 1986. Effect of oxytocin, prostaglandin F2 alpha and reproductive tract manipulations on uterine contractility in Holstein cows on days 0 and 7 of the estrous cycle. J. Anim. Sci. 63: 151-161. [Medline] [CrossRef]

9. de Boer, M. W., LeBlanc, S. J., Dubuc, J., Meier, S., Heuwieser, W., Arlt, S., Gilbert, R. O. and McDougall, S. 2014. Invited review: Systematic review of diagnostic tests for reproductive-tract infection and inflammation in dairy cows. J. Dairy Sci. 97: 3983-3999. [Medline] [CrossRef]

10. Dubuc, J., Duffield, T. F., Leslie, K. E., Walton, J. S. and LeBlanc, S. J. 2012. Risk factors and effects of postpartum anovulation in dairy cows. J. Dairy Sci. 95: 1845-1854. [Medline] [CrossRef]

11. Eiler, H., Hopkins, F. M., Armstrong-Backus, C. S. and Lyke, W. A. 1984. Uterotonic effect of prostaglandin F2 alpha and oxytocin on the postpartum cow. Am. J. Vet. Res. 45: 1011-1014. [Medline]

12. Ferguson, S. S., Barak, L. S., Zhang, J. and Caron, M. G. 1996. G-protein-coupled receptor regulation: role of G-protein-coupled receptor kinases 
and arrestins. Can. J. Physiol. Pharmacol. 74: 1095-1110. [Medline] [CrossRef]

13. Fuchs, A. R., Rollyson, M. K., Meyer, M., Fields, M. J., Minix, J. M. and Randel, R. D. 1996. Oxytocin induces prostaglandin F2 alpha release in pregnant cows: influence of gestational age and oxytocin receptor concentrations. Biol. Reprod. 54: 647-653. [Medline] [CrossRef]

14. Gilbert, R. O., Shin, S. T., Guard, C. L., Erb, H. N. and Frajblat, M. 2005. Prevalence of endometritis and its effects on reproductive performance of dairy cows. Theriogenology 64: 1879-1888. [Medline] [CrossRef]

15. Goto, A., Nakada, K. and Katamoto, H. 2016. The association of culling and death rate within 30 days after calving with productivity or reproductive performance in dairy herds in Fukuoka, Southern Japan. J. Vet. Med. Sci. 78: 587-592. [Medline] [CrossRef]

16. Haimerl, P., Arlt, S. and Heuwieser, W. 2012. Evidence-based medicine: quality and comparability of clinical trials investigating the efficacy of prostaglandin $\mathrm{F}_{2 \alpha}$ for the treatment of bovine endometritis. J. Dairy Res. 79: 287-296. [Medline] [CrossRef]

17. Hickey, G. J., White, M. E., Wickenden, R. P. and Armstrong, D. A. 1984. Effects of oxytocin on placental retention following dystocia. Vet. Rec. 114: 189-190. [Medline] [CrossRef]

18. Hirsbrunner, G., Burkhardt, H. W. and Steiner, A. 2006. Effects of a single administration of prostaglandin F2alpha, or a combination of prostaglandin F2alpha and prostaglandin E2, or placebo on fertility variables in dairy cows 3-5 weeks post partum, a randomized, double-blind clinical trial. Reprod. Biol. Endocrinol. 4: 65. [Medline] [CrossRef]

19. Hirsbrunner, G., Küpfer, U., Burkhardt, H. and Steiner, A. 1998. Effect of different prostaglandins on intrauterine pressure and uterine motility during diestrus in experimental cows. Theriogenology 50: 445-455. [Medline] [CrossRef]

20. Kamimura, S., Ohgi, T., Takahashi, M. and Tsukamoto, T. 1993. Postpartum resumption of ovarian activity and uterine involution monitored by ultrasonography in Holstein cows. J. Vet. Med. Sci. 55: 643-647. [Medline] [CrossRef]

21. Kasimanickam, R., Duffield, T. F., Foster, R. A., Gartley, C. J., Leslie, K. E., Walton, J. S. and Johnson, W. H. 2004. Endometrial cytology and ultrasonography for the detection of subclinical endometritis in postpartum dairy cows. Theriogenology 62: 9-23. [Medline] [CrossRef]

22. Kasimanickam, R., Duffield, T. F., Foster, R. A., Gartley, C. J., Leslie, K. E., Walton, J. S. and Johnson, W. H. 2005. A comparison of the cytobrush and uterine lavage techniques to evaluate endometrial cytology in clinically normal postpartum dairy cows. Can. Vet. J. 46: 255-259. [Medline]

23. LeBlanc, S. J. 2008. Postpartum uterine disease and dairy herd reproductive performance: a review. Vet. J. 176: 102-114. [Medline] [CrossRef]

24. LeBlanc, S. J., Duffield, T. F., Leslie, K. E., Bateman, K. G., Keefe, G. P., Walton, J. S. and Johnson, W. H. 2002. Defining and diagnosing postpartum clinical endometritis and its impact on reproductive performance in dairy cows. J. Dairy Sci. 85: 2223-2236. [Medline] [CrossRef]

25. Lindell, J. O. and Kindahl, H. 1983. Exogenous prostaglandin F2 alpha promotes uterine involution in the cow. Acta Vet. Scand. $24: 269-274$. [Medline]

26. Madej, A., Kindahl, H., Woyno, W., Edqvist, L. E. and Stupnicki, R. 1984. Blood levels of 15-keto-13, 14-dihydroprostaglandin $\mathrm{F}_{2 \alpha}$ during the postpartum period in primiparous cows. Theriogenology 21: 279-287. [Medline] [CrossRef]

27. Marion, G. B., Norwood, J. S. and Gier, H. T. 1968. Uterus of the cow after parturition: factors affecting regression. Am. J. Vet. Res. $29: 71-75$. [Medline]

28. Martin, L. R., Williams, W. F., Russek, E. and Gross, T. S. 1981. Postpartum uterine motility measurements in dairy cows retaining their fetal membranes. Theriogenology 15: 513-524. [Medline] [CrossRef]

29. McDougall, S., Macaulay, R. and Compton, C. 2007. Association between endometritis diagnosis using a novel intravaginal device and reproductive performance in dairy cattle. Anim. Reprod. Sci. 99: 9-23. [Medline] [CrossRef]

30. Miller, B. J. and Lodge, J. R. 1984. Postpartum oxytocin treatment for prevention of retained placentas. Theriogenology 22: 385-388. [Medline] [CrossRef]

31. Morrow, D. A., Roberts, S. J. and McEntee, K. 1969. Postpartum ovarian activity and involution of the uterus and cervix in dairy cattle. 1. Ovarian activity. Cornell Vet. 59: 173-190. [Medline]

32. Okano, A. and Tomizuka, T. 1987. Ultrasonic observation of postpartum uterine involution in the cow. Theriogenology 27: 369-376. [Medline] [CrossRef]

33. Opsomer, G., Gröhn, Y. T., Hertl, J., Coryn, M., Deluyker, H. and de Kruif, A. 2000. Risk factors for post partum ovarian dysfunction in high producing dairy cows in Belgium: a field study. Theriogenology 53: 841-857. [Medline] [CrossRef]

34. Palomares, R. A., Gutiérrez, J. C., Portillo, G., Boscan, J. C., Montero, M., López, Y., Maxwell, H. S., Carson, R. L. and Soto, E. 2010. Oxytocin treatment immediately after calving does not reduce the incidence of retained fetal membranes or improve reproductive performance in crossbred Zebu cows. Theriogenology 74: 1414-1419. [Medline] [CrossRef]

35. Patil, R. K., Sinha, S. N., Einarsson, S. and Settergren, I. 1980. The effect of prostaglandin F2 alpha and oxytocin on bovine myometrium in vitro. Nord. Vet. Med. 32: 474-479. [Medline]

36. Perumamthadathil, C. S., Johnson, W. H., Leblanc, S. J., Foster, R. A. and Chenier, T. S. 2014. Persistence of oxytocin receptors in the bovine uterus during the first $7 \mathrm{~d}$ after calving: an immunohistochemical study. Can. J. Vet. Res. 78: 72-77. [Medline]

37. Phaneuf, S., Asbóth, G., MacKenzie, I. Z., Melin, P. and López Bernal, A. 1994. Effect of oxytocin antagonists on the activation of human myometrium in vitro: atosiban prevents oxytocin-induced desensitization. Am. J. Obstet. Gynecol. 171: 1627-1634. [Medline] [CrossRef]

38. Plested, C. P. and Bernal, A. L. 2001. Desensitisation of the oxytocin receptor and other G-protein coupled receptors in the human myometrium. Exp. Physiol. 86: 303-312. [Medline] [CrossRef]

39. Salasel, B. and Mokhtari, A. 2011. Effect of early postpartum PGF2 $\alpha$ treatment on reproductive performance in dairy cows with calving and puerperal traits. Theriogenology 76: 1723-1729. [Medline] [CrossRef]

40. Schams, D., Schmidt-Polex, B. and Kruse, V. 1979. Oxytocin determination by radioimmunoassay in cattle. I. Method and preliminary physiological data. Acta Endocrinol. 92: 258-270. [Medline] [CrossRef]

41. Sheldon, I. M., Noakes, D. E., Rycroft, A. N. and Dobson, H. 2003. The effect of intrauterine administration of estradiol on postpartum uterine involution in cattle. Theriogenology 59: 1357-1371. [Medline] [CrossRef]

42. Sheldon, I. M., Williams, E. J., Miller, A. N., Nash, D. M. and Herath, S. 2008. Uterine diseases in cattle after parturition. Vet. J. 176: 115-121. [Medline] [CrossRef]

43. Silvestre, F. T., Bartolome, J. A., Kamimura, S., Arteche, A. C., Pancarci, S. M., Trigg, T. and Thatcher, W. W. 2009. Postpartum suppression of ovarian activity with a Deslorelin implant enhanced uterine involution in lactating dairy cows. Anim. Reprod. Sci. 110: 79-95. [Medline] [CrossRef]

44. Stolla, R. and Schmid, G. 1990. [Effects of natural and synthetic PGF2 alpha preparations on the uterine contractility of cattle]. Berl. Munch. Tierarztl. Wochenschr. 103: 198-202. [Medline]

45. Thatcher, W. W., Bilby, T. R., Bartolome, J. A., Silvestre, F., Staples, C. R. and Santos, J. E. 2006. Strategies for improving fertility in the modern dairy cow. Theriogenology $65: 30-44$. [Medline] [CrossRef]

46. Toni, F., Vincenti, L., Ricci, A. and Schukken, Y. H. 2015. Postpartum uterine diseases and their impacts on conception and days open in dairy herds in Italy. Theriogenology 84: 1206-1214. [Medline] [CrossRef] 